* Mestre em Direito Negocial pela Universidade Estadual de Londrina (UEL). Doutorando na Faculdade de Direito - Universidade de Lisboa (FDUL), em Portugal. Coordenador e professor da Escola da Magistratura do Paraná - Núcleo Londrina. Professor da Fundação Escola do Ministério Público (FEMPAR) - Núcleo Londrina. Professor da Escola Superior de Advocacia (ESA) - Regional Londrina. Professor do Instituto de Direito Constitucional e Cidadania (IDCC). Professor da Universidade Estadual de Londrina (UEL), no curso de especialização. Juiz de Direito no Paraná.

E-mail: jricardo@sercomtel. com.br

\section{A CIÊNCIA (PURA) DO DIREITO EM HANS KELSEN}

THE SCIENCE (PURE) LAW ON HANS KELSEN

\section{José Ricardo Alvarez Vianna*}

Como citar: VIANNA, José Ricardo Alvarez. A ciência (pura) do direito em Hans Kelsen. Revista do Direito Público, Londrina, v. 11, n. 2, p.82-108, ago. 2016. DOI: 10.5433/1980-511X.2016v11n2p82. ISSN: 1980-511X.

RESUMO: o artigo analisa os motivos pelos quais Kelsen pretendia formatar uma ciência jurídica e os critérios e conceitos utilizados nessa empreitada. São examinados conceitos como norma jurídica e proposição jurídica, causalidade e imputação, estática e dinâmica jurídicas, além do papel da Norma Fundamental na estrutura lógica do sistema jurídico de acordo com a Teoria Pura do Direito. São analisadas, ainda, as conexões entre Direito, Justiça e ciência jurídica segundo Kelsen. Por fim, pretende-se apontar qual o legado da Teoria Pura do Direito.

Palavras-chave: Teoria Pura do Direito Ciência Jurídica - Hans Kelsen. 
ABSTRACT: the article analyzes the reasons why Kelsen wanted to form a Legal Science and the criteria and concepts used in his works. We examined concepts as legal norm and legal proposition, causality and imputation, static and dynamic of Law, beyond the role of the Basic Norm in the logical structure of the legal system according to the Pure Theory of Law. We analyzed, also, the connections between Law and Justice in the Legal Science according to Kelsen. Finally, it intends to show the legacy of the Pure Theory of Law.

Keywords: Pure Theory of Law - Legal Science - Hans Kelsen. 


\section{INTRODUÇÃO}

Ubi societas, ibi jus (onde está a sociedade, está o Direito), já assentava o antigo brocardo. Mas qual Direito? Direito natural ou Direito positivo? Ou seriam ambos? Como o Direito deve ser exposto e aplicado para possibilitar o convívio social em harmonia? Qual a relação entre Direito e Justiça? O que é Justiça?

Estas são questões que nunca cessam e para as quais existem muitas respostas, daí a importância de conhecer os grandes pensadores do Direito. Saber como eles lidaram com estes questionamentos e quais suas propostas teóricas em sede de respostas.

Dentre esses grandes pensadores, inequivocamente, está Hans Kelsen e sua obra magna: a Teoria Pura do Direito. Em razão disso, o presente artigo pretende analisar alguns dos elementos essenciais da Teoria Pura. Buscar entender porque Kelsen separou Direito de Justiça, se é que, de fato, separou. Compreender quais as razões que o levaram a arquitetar uma ciência jurídica e quais as bases conceituais utilizadas para tanto.

Para realizar essa tarefa é imprescindível compreender na teoria kelseniana conceitos como causalidade e imputação, linguagem e metalinguagem, norma jurídica e proposição jurídica, a estática e a dinâmica jurídicas, além de precisar o que vem a ser, realmente, a Norma Fundamental e qual sua relação com validade ou invalidade das normas jurídicas em geral.

A rigor, o artigo em pauta tem um objetivo mais específico. Tem o intento de responder à seguinte indagação: qual o grande legado da Teoria Pura do Direito de Hans Kelsen?

Em termos metodológicos, para realização do trabalho foi realizada pesquisa bibliográfica, tanto da própria Teoria Pura do Direito, como de outras obras de Hans Kelsen. Foram consultadas, igualmente, obras de outros autores que se dedicaram ao estudo do pensamento de Kelsen, além daquelas que, direta ou indiretamente, receberam sua influência. 


\section{POR QUE CONHECER A TEORIA PURA DO DIREITO DE KELSEN?}

Segundo Julius Hermann Von Kirchmann (apud NOVELLI, 2006, p. 103-109): "três palavras retificadoras do legislador convertem bibliotecas inteiras em lixo". A assertiva do jurista alemão do Século XIX comporta mais de uma interpretação. Uma das possíveis interpretações permite afirmar que o Direito não deve ser estudado somente a partir das regras dogmáticas que o integram, uma vez que as regras, por representarem apenas sua superfície, quando revogadas, deixam de ter conteúdo coercitivo ou mesmo qualquer relevância jurídica social. ${ }^{1}$

O Direito, portanto, deve ser estudado a partir de seus fundamentos; de seus conceitos essenciais que lhe dão suporte, operacionalidade e substância. Em suma: conceitos que possibilitam o Direito alcançar seu objetivo primordial: a convivência social pacífica. Segundo Rudolf von Ihering: "o fim do direito é a paz" (IHERING, 2000, p. 27).

Kelsen neste quesito não desaponta. A Teoria Pura do Direito (Reine Rechtslehre) é toda alinhavada com base nos fundamentos do Direito. Mais do que isto: suas premissas e conceitos levaram em conta a natureza e a condição humanas, o que lhe confere coerência e força.

A Teoria Pura do Direito é uma obra que foi trabalhada e lapidada durante grande parte da vida de seu autor e constitui um dos grandes marcos para o Direito. A obra foi escrita e reescrita conforme avançavam as reflexões de Kelse sobre Direito, sociedade e ser humano.

Uma primeira versão da Teoria Pura foi publicada em 1934. Não obstante, suas bases teóricas já haviam sido lançadas em outra obra jurídica de Kelsen, denominada Problemas Fundamentais de Direito Público (Hauptprobleme der Staatsrechtsehre entwickelt aus der Lehre vom Rechtssatze), publicada em 1911.

Em 1960, a Teoria Pura contou com nova versão revisada, alterada e ampliada, e reflete uma visão amadurecida das ideias inaugurais. Não bastasse isto, há uma obra publicada postumamente,

1 O pronunciamento de Kirchmann teve o intuito negar a existência de uma ciência jurídica. Não obstante, como assinalado, a frase pode receber outras interpretações. 
em 1979, intitulada Teoria Geral das Normas (Alllgemeine Theorie der Normen), na qual vários temas da Teoria Pura tornam a ser revisitados e reexaminados (ROBLES, 1934, p. 29-30). ${ }^{2}$

Como se pode constatar, as ideias da Teoria Pura do Direito permearam, basicamente, toda a vida acadêmica de Kelsen, o que demonstra seu elevado compromisso e seriedade no tratar dos temas ali apresentados.

Ainda hoje, muitas ideias desenvolvidas na Teoria Pura de Kelsen continuam a ter forte influência. Basta lembrar da concepção de estrutura escalonada (Stufenbau) do Direito; do conceito de Norma Fundamental (Grundnorm), da distinção entre vigência e eficácia da norma jurídica ou dos conceitos de norma jurídica e proposição jurídica. $\mathrm{O}$ mesmo se diga de conceitos como intérprete autêntico e moldura jurídica da norma, todos presentes nos curso de Direito, mundo afora.

Apesar disso, suas ideias nem sempre são compreendidas, seja por desconhecimento, seja por equívocos interpretativos. Por vezes se depara com afirmações no sentido de que a Norma Fundamental corresponde à Constituição ou de que Kelsen, como positivista, defendia a interpretação literal da lei, o que não corresponde à realidade.

$\mathrm{O}$ fato é que Kelsen foi um pensador ímpar do Direito. Sempre se postou de modo independente frente a quaisquer segmentos sociais. Prova disso é que a Teoria Pura do Direito foi criticada por inúmeros desses segmentos, conforme ele próprio deixou registrado no prefácio à primeira edição da obra. Observe-se:

Os fascistas declaram-na liberalismo democrático, os democratas liberais ou os sociais-democratas consideram-na um posto avançado do fascismo. Do lado comunista é desclassificada como ideologia de um estatismo capitalista; do lado capitalistanacionalista é desqualificada, já como bolchevismo crasso, já como anarquismo velado. O seu espírito é asseguram muitos - aparentado com o da escolástica católica; ao passo que outros crêem reconhecer nela

2 Hans Kelsen nasceu em Praga, a 11/10/1881; e faleceu em Berkeley, a 19 de abril de 1973. 
as características distintivas de uma teoria protestante do Estado e do Direito. E não falta também quem a pretenda estigmatizar com a marca de ateísta. (KELSEN, 2000, p. XIII).

Tais críticas não só demonstram a independência do pensador como evidenciam que ele tocou em pontos nevrálgicos do Direito com reflexos em toda a sociedade. Sua obra não passou indiferente a qualquer setor. Por conta disso, conhecer o pensamento de Kelsen é ter acesso aos motivos que o levaram a formular sua proposta para uma ciência do Direito; saber em que medida e por quais razões ele fez a cisão entre Direito positivo e Justiça; entender o porquê da imprescindibilidade do formalismo jurídico; compreender a importância de uma articulação estrutural do Direito que, a um só tempo, fornece critérios para este se constituir e se reconstituir validamente.

Em síntese: conhecer o pensamento de Kelsen e sua Teoria Pura do Direito importa em aprender um pouco mais do Direito e de Direito; não em sua superfície, e sim em seus fundamentos; autênticos pilares que o estruturam e o constituem.

\section{A PUREZA TEÓRICA E A METALINGUAGEM DA CIÊNCIA JURÍDICA}

Kelsen ao realizar a purificação teórica do Direito visava apresentar bases sólidas para a edificação de uma genuína ciência do Direito. Aspirava uma ideia universal de ciência jurídica; universalidade, aliás, própria das ciências em geral. Isto fica claro quando ele diz: "a Teoria Pura do Direito é uma teoria do Direito positivo - do Direito positivo em geral, não de uma ordem jurídica especial. É teoria geral do Direito, não interpretação de particulares normas jurídicas, nacionais ou internacionais" (KELSEN, 2000, p. 1).

Para Karl Larenz (2009, p. 92): “A sua 'teoria pura do Direito' constitui a mais grandiosa tentativa de fundamentação da ciência do Direito como ciência."

Nessa linha, Adrian Sgarbi (2009, p. 31) abona: “a Teoria Pura 
do Direito não é apenas o nome de um livro, mas de um projeto; projeto de elevar o direito à posição de "ciência jurídica"'.

Para melhor compreender esta preocupação de Kelsen é importante ter presente que, até então, prevalecia uma miscigenação metodológica no Direito, reflexo de uma fraca consciência e débil formação epistemológica jurídicas, agravadas pela demasiada e aleatória influência de fatores políticos, econômicos ou axiológicos no Direito.

Várias foram as Escolas do pensamento jurídico, em especial nos Séculos XVIII e XIX, que buscavam fórmulas para lidar com questões jurídicas. Dentre estas podem ser lembradas a Escola da Exegese, a Escola Histórica do Direito, a Escola da Livre Pesquisa do Direito e a Escola do Direito Livre (REALE, 1988). No entanto, nenhuma delas apresentou respostas aptas o suficiente para os problemas jurídico-sociais. Ao revés, suas propostas abriam margem para concepções solipsistas do Direito e em sua aplicação.

Para Kelsen tais Escolas jurídicas confundiam sociologia, psicologia, ética e política com Direito e nisto residia suas inconsistências. Era preciso demarcar com traços fortes o solo do jurídico, de modo a firmar condições de sua operacionalidade; de sua criação e renovação, sem se deixar turvar por ruídos alheios e estranhos a seu objeto; caso contrário, em vez de contribuir para a segurança jurídica, abalavam-na. Era necessário um "princípio metodológico fundamental" (KELSEN, 2000 , p. 1), e isto somente poderia ser obtido por meio de uma ciência jurídica.

Foi assim que Kelsen se valeu do conceito de pureza em sua construção teórica. Seu objetivo era estabelecer um "conhecimento apenas dirigido ao Direito e excluir tudo quanto não pertença a seu objeto" (KELSEN, 2000, p. 1).

Com base nisto Kelsen vai afirmar que ciência jurídica e Direito não se confundem. Pare ele o Direito não é uma ciência, mas objeto de estudo de uma ciência: a ciência do Direito (GRAU, 2008, p. 36). A ciência do Direito quer conhecer o seu objeto: o Direito positivo. O que é puro, nesta concepção, é a ciência jurídica, e não o Direito positivo. Neste particular, veja o ele diz: 
Há mais de duas décadas que empreendi desenvolver uma teoria jurídica pura, isto é, purificada de toda ideologia e de todos os elementos de ciência natural, uma teoria jurídica consciente da legalidade específica de seu objeto. Logo desde o começo foi o meu intento elevar a Jurisprudência, que - aberta ou veladamente - se esgotava quase por completo em raciocínios de política jurídica, à altura de uma genuína ciência, de uma ciência do espírito. Importava explicar, não as suas tendências exclusivamente dirigidas ao conhecimento do Direito, e aproximar tanto quanto possível os seus resultados do ideal de toda a ciência: objetividade e exatidão (KELSEN, 2000, p. XI).

A distinção entre ciência do Direito e Direito positivo tornase mais clara com a compreensão do que vem a ser linguagem-objeto e metalinguagem. Nesta conformação, a ciência do Direito equivale à metalinguagem que se propõe a descrever e analisar o Direito positivo que é sua linguagem-objeto (KELSEN, 2000, p. 79-80).

Sobre o tema, Juan-Ramon Capela anota:

a Teoria da Hierarquia da Linguagem coloca como postulado para distinguir uma linguagem dada de outra linguagem que se fala dela. Se ' $L$ ' e ' $M$ ' são duas linguagens, e em linguagem ' $M$ ' se fala da linguagem ' $L$ ', atuando ' $L$ ' como objeto da linguagem ' $M$ ', chamaremos a ' $L$ ' de linguagem-objeto de ' $M$ ', e a 'M' de metalinguagem de 'L'. (CAPELLA, 1968. p. 30).

Desse modo, Kelsen isola da ciência do Direito outros fatores que possam interferir ou toldar a análise e compreensão do Direito normatizado. O que importa, nesta óptica, são os elementos, as características, os aspectos que compõem o Direito normatizado, e não 
considerações estranhas a este.

Ancorado nesse raciocínio, Kelsen formula uma de suas importantes bases teóricas, qual seja: distinção entre norma jurídica (Rechtsnorm) e proposição jurídica (Rechtssatz).

A norma jurídica para Kelsen consiste na linguagem-objeto (Direito positivo), enquanto a proposição jurídica corresponde à metalinguagem. Segundo Eduardo C. B. Bittar e Guilherme Assis de Almeida: "Para o positivismo Kelseniano, a norma jurídica é o alfa $(\alpha)$ e o ômega $(\Omega)$ do sistema normativo, ou seja, o princípio e o fim de todo o sistema." (BITTAR, 2010, p. 390).

Logo, não há como confundir a atividade do aplicador do Direito daquela desenvolvida pelo cientista jurídico. A norma jurídica prescreve a conduta a ser realizada; a proposição jurídica descreve a norma jurídica (KELSEN, 2000, p. 80-84).

Para deixar isto mais palpável, tome-se como exemplo a norma jurídica prevista no artigo 121 do Código Penal, a qual estabelece: "matar alguém: Pena - reclusão, de seis a vinte anos". Como se pode ver, a norma jurídica prescreve um comando.

Já proposição jurídica (metalinguagem) respectiva irá se ocupar em descrever referida norma jurídica. Assim, o cientista do Direito ao afirmar que "o crime de homicídio deverá ser punido com pena de reclusão que varia entre 6 (seis) a 20 (vinte) anos", editará uma proposição jurídica e esta proposição será verdadeira; por outro lado, se disser que "o crime de homicídio deverá ser punido com pena de multa"; então a proposição (metalinguagem), por não descrever com fidelidade o conteúdo - antecedente e consequente da norma jurídica (linguagem-objeto) - , será falsa.

A distinção entre norma jurídica e proposição jurídica é de suma importância na Teoria Pura em termos científicos. Com base neste critério será possível aferir a validade ou invalidade de soluções jurídicas e/ou de 
normas jurídicas no contexto do ordenamento jurídico sistematizado. $\mathrm{E}$ o mais importante: a aferição dessa validade ou invalidade se manifesta apoiada em parâmetros epistemológicos, e não em fatores axiológicos.

Por ora, cabe reiterar que o principal objetivo da Teoria Pura do Direito é constituir uma ciência jurídica que estuda e descreve o Direito positivo, sem interferências externas e com maior objetividade possível, sob pena que não haver ciência, mas mera opinião (doxa).

\section{AIMPUTAÇÃO COMO PRESSUPOSTO À CIÊNCIAJURÍDICA}

Para estabelecer uma ciência do Direito não bastava Kelsen identificar seu objeto e estudá-lo, com rigor e objetividade, por intermédio de uma linguagem descritiva. Era necessário, também, distinguir este objeto de outros objetos próprios das ciências naturais, haja vista que o Direito contém características peculiares se comparado às ciências naturais.

Por outras palavras: as leis naturais e as normas jurídicas pertencem a ontologias diversas. As leis naturais estão no plano do ser no qual impera uma relação de causa e efeito. Assim, um copo cheio de água, uma vez submetido à temperatura abaixo de zero, terá seu líquido vertido para estado sólido; congelará. Por outras palavras, ocorrido o antecedente será o consequente. A isto se dá o nome de princípio da causalidade (KELSEN, 2000, p. 85).

Por conta disso, segundo Kelsen (2000, p. 85) só haveria uma ciência jurídica, diversa das ciências naturais, se ela descrevesse seu objeto segundo um princípio específico, distinto do princípio da causalidade. 
É assim que emerge a fórmula geral da imputação, de matriz kantiana. Assim como nas leis naturais, no Direito também há uma conexão ligando dois pontos - antecedente e consequente -, porém esta conexão não se firma com base na causalidade das ciências da natureza, mas na imputação (Zurechnung), e são conectadas pelo dever ser (Sollen) contido na norma jurídica. Logo, se alguém não cumpre uma obrigação no tempo, lugar e forma devidos, deverá responder com seu patrimônio por sua inadimplência; ou ainda: se alguém comete um crime, deverá sofrer a sanção criminal correspondente (KELSEN, 2000, p. 86).

Nas normas jurídicas não impera o ser (Sein), enquanto mediador entre causa e efeito, mas o dever ser (Sollen). A relação é de imputação, e não de causalidade (HONESKO, 2006, p. 85; VILANOVA, 2000, p. 29).

Como afirma Henrique Garbellini Carnio (2013, p. 98): "Se há uma ciência social que é diferente da ciência natural, ela deve descrever seu objeto diferentemente do princípio de causalidade, ou melhor, não apenas a partir dele." Deste modo, tem-se "o direito como norma, ou seja, como sistema de normas, e limitando a ciência jurídica ao conhecimento e descrição dessas normas jurídicas e às relações por estas constituídas" (CARNIO, 2013, p. 99).

Estas premissas serão essenciais no trabalho do cientista do Direito no momento deste aferir a validade ou invalidade das soluções jurídicas a partir do conteúdo da norma jurídica. Além do mais, em certa medida, há uma compatibilização do princípio da imputação com os conceitos de norma jurídica e proposição jurídica. Sim, porque a proposição jurídica irá descrever a prescrição contida na norma jurídica, 
que, por sua vez, ocorre com base na imputação (deôntica), e não na causalidade.

Para finalizar este tópico, cumpre averbar que a ciência jurídica é uma ciência do dever ser, e não do ser. Kelsen realiza, assim, a ruptura entre causalidade e imputação, e confere autonomia à ciência jurídica frente às ciências naturais.

Andityas Soares de Moura Costa Matos (2006, p. 92) sublinha que a opção metodológica de Kelsen tomou como pressuposto três condições: $1^{\mathrm{a}}$ ) delimitação rigorosa do campo de estudos; $2^{\mathrm{a}}$ ) ausência absoluta de juízos de valor e $3^{\text {a }}$ ) neutralidade do cientista.

\section{JUSTIÇA E CIÊNCIA DO DIREITO}

Um dos pontos de maior crítica em relação à Teoria Pura de Kelsen diz respeito à sua radical cisão entre Justiça e Direito. Em decorrência dessas críticas, por vezes chega-se ao extremo de atribuir a Kelsen a responsabilidade por haver legitimado juridicamente as mazelas do nazismo.

A crítica não procede, todavia.

Inicialmente, é preciso ter presente que Kelsen jamais apresentou qualquer vínculo com o nazismo. Um simples olhar em sua biografia permite concluir que ele, dada sua ascendência judaica, foi vítima do nazismo. Por várias ocasiões foi forçado a se mudar de cidades e de países pela Europa até, finalmente, emigrar para os Estados Unidos em 1940, local onde veio a falecer em 1973 (KELSEN, 2008).

De qualquer modo, antes de se criticar precipitadamente o pensamento de Kelsen é preciso conhecer as razões que o levaram a defender certas ideias.

Kelsen nunca foi contra a Justiça, muito menos de sua existência e aplicação no Direito. Prova disso está no fato dele haver escrito 3 
(três) obras tratando especificamente sobre Justiça, sem jamais negá-la ou afastá-la do Direito. ${ }^{3}$

Para entender os motivos do equívoco sobre seu pensamento é necessário ter em conta três aspectos: a) Justiça relativa; b) ciência do Direito; c) Justiça no Direito positivo.

Passa-se a exame de cada uma:

a) Justiça relativa. Para Kelsen não existe uma Justiça absoluta. Toda visão de Justiça é relativa, porquanto está imbuída de um olhar dotado de valores pessoais, contingenciais, circunstanciais. O que é justo para uns, não é justo para outros e assim sucessivamente, de maneira que é impossível firmar um consenso absoluto de Justiça.

Para evitar qualquer dúvida acerca deste ponto no pensamento do mestre de Viena ${ }^{4}$, convém transcrever suas próprias palavras nas quais ele, além de rejeitar a ideia da existência de uma Justiça absoluta, ainda expõe o que ele entende por Justiça. Observe-se:

De fato, não sei e não posso dizer o que seja justiça, a justiça absoluta, esse belo sonho da humanidade. Devo satisfazer-me com uma justiça relativa, e só posso declarar o que significa justiça para mim: uma vez que a ciência é minha profissão e, portanto, a coisa mais importante em minha vida, trata-se daquela justiça sob cuja proteção a ciência pode prosperar e, ao lado dela, a verdade e a sinceridade. É a justiça da liberdade, da paz, da democracia, da tolerância. (KELSEN, 2001, p. 25).

Observe-se que o próprio Kelsen traz uma ideia particular de Justiça, o que confirma a relatividade do conceito. Isto, por certo, tem reflexos na elaboração de uma ciência jurídica.

b) Ciência do Direito. O propósito de Kelsen consistia em

3 É o caso das obras $O$ Problema da Justiça, O que é Justiça? e A Ilusão da Justiça.

4 Kelsen nasceu, de fato, em Praga. Mas seu nascimento se deu durante o Império Austro-Húngaro. Além disso, sua família mudou-se para Viena quando ele contava com apenas 3 (três) anos de idade. Foi em Viena que Kelsen realizou grande parte de sua formação jurídica; onde foi professor da Faculdade de Direito local, assim como onde atuou como membro da Corte Constitucional, entre 1920 a 1930. Logo, não há equívoco na expressão mestre de Viena. 
estabelecer padrões à existência de uma ciência do Direito. Para isto era preciso assegurar a neutralidade do cientista do Direito, e considerações de ordem axiológica poderiam contaminar os resultados da investigação. O trabalho do cientista, assim, deve se circunscrever à descrição do objeto estudado (Direito positivo), e não na valoração deste. Kelsen deixa isto evidente na seguinte passagem:

O cientista jurídico não tem a escolha de aceitar ou rejeitar o Direito, tal como estabelecido pelo legislador, com base no seu juízo sobre o que é justo e injusto. O cientista tem de descrever a decisão do legislador como Direito existente, considerando-o em conformidade ou não com o que considera justiça. Ele pode apenas examinar se as normas criadas pelo órgão legislativo estão ou não em conformidade com as normas positivas da constituição, e o resultado desse exame é, em última análise, a verificação objetiva de um fato, não um juízo subjetivo de valor. (KELSEN, 2001, p. 365).

Sinteticamente: na atividade do cientista do Direito não deve haver juízos de valor em relação a seu objeto (Direito positivo).

c) Justiça no Direito positivo. Por não existir um conceito absoluto, unívoco e universal de Justiça e para não ofuscar ou comprometer o trabalho do cientista do Direito, a compreensão ou as pré-compreensões do que seja justo/injusto devem ser afastadas de sua atividade. Mas o que dizer do Direito positivo? O Direito positivo deve ou não ser justo? O que diz Kelsen, afinal?

Aqui reside um dos aspectos mais importantes da Teoria Pura do Direito. Kelsen, em momento algum, afirmou que Direito positivo não deve ser justo sob certa perspectiva, tampouco que não possa conter enunciados que expressem certos valores morais. Contudo, salientou que isto é matéria a ser debatida por ocasião do momento em que tais valores se tornarão Direito positivo; no momento em que tais valores ingressarão no sistema jurídico. Novamente, é de bom alvitre colacionar as palavras 
do jurista de Viena para evitar desacertos:

Um Direito positivo pode ser justo ou injusto; a possibilidade de ser justo ou injusto é uma consequência essencial do fato de ser positivo. (...) Normalmente, o órgão legislativo é juridicamente obrigado pela Constituição apenas no que diz respeito ao processo legislativo. O conteúdo das normas a serem criadas pelo órgão legislativo apenas excepcionalmente é determinado pela Constituição. (...) $\mathrm{Na}$ medida em que a função legislativa não é determinada pela Constituição, o legislador pode ser, e efetivamente é, determinado por princípios políticos, especialmente pela sua ideia de justiça. Ele pode preferir um preceito a outro no mesmo campo, porque considera um justo e o outro injusto. (KELSEN, 2001, p. 364-365).

É interessante enfatizar que Kelsen não exclui sequer a atividade judicial da busca pela Justiça, desde que o juiz exerça suas funções com base no Direito positivo. Veja o que ele diz:

Mas há sempre uma esfera de arbítrio mais ampla ou mais estreita, deixada pela norma jurídica superior à função criadora de Direito de um tribunal e, dentro dessa esfera de arbítrio, a decisão judicial pode ser, e efetivamente é, determinada por outras normas que não as do Direito positivo. Ao criar uma norma individual pela jurisprudência, o tribunal tem sempre a escolha de diferentes decisões possíveis dentro da estrutura da norma geral que determina a função judicial. O tribunal pode preferir uma a outra porque considera uma justa e a outra injusta. Mas o cientista jurídico não tem tal escolha. (KELSEN, 2001, p. 366).

Como se percebe, o afastamento de considerações sobre o justo 
ou sobre valores de ordem moral tem uma razão de ser na Teoria Pura, qual seja: constituir uma ciência do Direito. Isto não quer dizer que o Direito positivo esteja alheio ou à margem que quaisquer concepções de Justiça. Não é isto. O que ocorre é que a noção de Justiça constante do Direito positivo, primeiro, será sempre relativa, jamais absoluta. Segundo, justo ou bom será o que consta do Direito positivo, de modo que ao intérprete e aplicador do Direito cabe buscar a solução justa nos limites do Direito; do Direito positivado; normatizado, e não mais no Direito natural ou em especulações metafísicas, muito menos em seus valores pessoais ou convicções íntimas. Isto representaria a mais completa insegurança jurídica, além de abrir margem a debates intermináveis e insolúveis.

Neste sentido, menciona-se:

Mas com isto não fica excluída a possibilidade da pretensão que exija que o Direito positivo deve harmonizar-se com um sistema moral e com ele venha eventualmente a concordar de fato, contradizendo um sistema moral diferente deste. Se, pressupondo a existência de valores meramente relativos, se pretende distinguir o Direito da Moral em geral e, em particular, distinguir o Direito da Justiça, tal pretensão não significa que o conceito de Direito não caiba no conceito de bom. Na verdade, o conceito de 'bom' não pode ser determinado senão como 'o que deve ser', o que corresponde a uma norma. (KELSEN, 2000, p. 75).

O legislador, por igual, não está impedido de editar um Direito positivo que repute justo. Pelo contrário, sua atuação será um divisor de águas a separar a discussão sobre o que é e o que não é justo; sobre o que deve e o que não deve se converter em Direito positivo; sim, porque uma vez positivada a conduta do dever ser na norma jurídica, cessará a discussão se ela é ou não justa por parte do cientista do Direito, além de que haverá elevado estreitamento na atuação jurisdicional, já que o juiz está vinculado ao Direito positivo. 
Nesse palmar, cumpre saber como ocorre, de acordo com a Teoria Pura, o ingresso desses valores, por vezes tão relativos, no Direito positivo, tema que remete ao exame dos princípios estático e dinâmico na Teoria de Kelsen. É o que será objeto de análise a seguir.

\section{A ESTÁTICA E A DINÂMICA KELSENIANAS}

Kelsen visava elaborar uma teoria apoiado em base estrutural sólida, porém não fechada e a alheia às mutações sociais. Um sistema jurídico que pudesse se recriar e se reconstituir, conforme as necessidades sociais.

Para dar cabo a esse desiderato, Kelsen formula dois conceitos. O primeiro consiste em conceber o Direito em sua dimensão estática; o segundo, em sua dimensão dinâmica. Em ambos, a lógica e o formalismo estão presentes a fim de se delinear um sistema jurídico propriamente dito.

O princípio estático concentra-se no exame da norma jurídica em si, e não no processo de criação desta. Toma como alvo o estudo da norma jurídica já existente, daí o vocábulo estático.

O exame da norma, em sua dimensão estática, é imprescindível à realização da ciência jurídica, pois sendo o Direito uma ordem de coerção, a análise de seus elementos é inafastável.

Nesta averiguação o cientista do Direito irá focar sua pesquisa em aspectos como sanção, ilícito, dever, responsabilidade, direito subjetivo, direitos pessoais e reais, interesse juridicamente protegido, direitos políticos, capacidade, representação, competência, poder jurídico etc.

A estática jurídica possibilita que seja feita uma radiografia de todo o conteúdo da norma jurídica e de seus efeitos. Com isso, a Teoria de Kelsen acaba por superar as dicotomias jurídicas existentes desde longa data no cenário jurídico, das quais podem ser lembradas as divisões entre direito público e direito privado, direito civil e penal. Doravante, não há norma jurídica penal e norma jurídica civil, não há direito público 
e direito privado; direito material e direito processual. Para Kelsen há apenas norma jurídica; todas as normas desses ramos do Direito são normas jurídicas e se revestem de certas características que lhe conferem o status de jurídicas. Este aspecto vem a confirmar o conteúdo universal da Teoria Pura (FERRAZ, 1994, p. 131-132).

O princípio dinâmico do ordenamento jurídico, por outro lado, concentra seus esforços no conjunto de normas jurídicas, e não na norma jurídica individual. Fará uma pesquisa acerca das relações de coordenação e subordinação entre as normas jurídicas, o que, novamente, remete ao conceito de sistema, pois se não houver sincronia na estrutura que lhe dá suporte, não há sistema jurídico.

Esta sincronia pressupõe hierarquia entre as normas jurídicas, hierarquia esta que irá proporcionará condições de aferir a esperada concatenação lógica entre as normas jurídicas.

A norma jurídica somente será reputada válida se emanar de ato legítimo de autoridade. $\mathrm{O}$ fundamento dessa validade será encontrado em outra norma superior que lhe confere suporte e assim sucessivamente, culminando naquilo que Kelsen nominou como Norma Fundamental (Grundnorm), idealizada para justificar o fundamento último de validade de todas as normas jurídicas. Por isso se diz que a Norma Hipotética Fundamental não consiste em uma norma posta, mas suposta; pressuposta (KELSEN, 2000, p. 296-297).

Esta estrutura escalonada permite não só aferir a validade ou invalidade de uma determinada norma jurídica no ordenamento jurídico, como fornece instrumental para edição de novas normas jurídicas por parte das autoridades competentes, desde que amparadas em norma jurídica que the reconheça tal competência.

Foi com base nisto que Kelsen (2000, p. 221) frisou que "todo e qualquer conteúdo pode ser Direito", e "não há qualquer conduta humana que, como tal, por força do seu conteúdo, esteja excluída de ser conteúdo de uma norma jurídica." Basta que sejam observados os requisitos para 
ingresso no ordenamento jurídico da conduta a ser prescrita pela norma jurídica.

Assim delineado o tema, reafirma-se que a discussão de temas de elevada carga axiológica, como a Justiça ou não de determinada norma jurídica está fora do campo da ciência do Direito. Esta discussão deve ocorrer no momento do ingresso do conteúdo da norma para o interior do ordenamento jurídico. Após, seu exame deve se circunscrever à sua validade ou não da norma jurídica de acordo com a estrutura hierárquica normativa prévia.

Outro elemento relevante da Teoria Pura de Kelsen reside no fato de que, a partir da estrutura piramidal do ordenamento jurídico, o juiz também tem o poder de criar (produzir) o Direito. Ao aplicar o Direito na solução de uma controvérsia com amparo em norma jurídica geral e abstrata; hipotética e condicional, o magistrado acaba por criar uma norma individual e concreta para solucionar a lide. Sobre este assunto, impõe-se a transcrição dos apontamentos de Kelsen:

A aplicação do Direito é simultaneamente produção do Direito. (...) É desacertado distinguir entre atos de criação e atos de aplicação do Direito. (...) Para individualizar a norma geral por ele aplicada, o tribunal tem de verificar se, no caso que se lhe apresenta, existem in concreto os pressupostos de uma consequência do ilícito determinados in abstracto por uma norma geral. (...) A norma individual, que estatui que deve ser dirigida contra um determinado indivíduo uma sanção, só é criada através da decisão judicial. Antes dela, não tinha vigência. Somente a falta de compreensão da função normativa da decisão judicial, o 
preconceito de que o Direito apenas consta de normas gerais, a ignorância da norma jurídica individual, obscureceu o fato de que a decisão judicial é tão-só a continuação do processo de criação jurídica e conduziu ao erro de ver nela apenas a função declarativa. (KELSEN, 2000, p. 260/265).

Em outra passagem, Kelsen não apenas confirma esta última assertiva, como estende este raciocínio de criação do Direito às resoluções administrativas e aos atos jurídicos negociais. Confira-se: “A aplicação do Direito existe tanto na produção de normas jurídicas gerais por via legislativa e consuetudinária como nas resoluções administrativas e ainda - como veremos - nos atos jurídico-negociais.” (KELSEN, 2000, p. 263).

O princípio dinâmico, portanto, para Kelsen tem dois propósitos: a) oferecer critérios para aferir se uma norma jurídica é ou não válida; b) fornecer condições para que o Direito positivo possa se renovar e se autoproduzir (selbasterseugung). Mais: o ordenamento jurídico, nesta conformação, passa a ser unitário, daí a exclusão das dicotomias direito penal, civil, administrativo ou processual. Há só um Direito e seu fundamento último reside na Norma Fundamental, conforme a estrutura estática e dinâmica que ordena e coordena o sistema jurídico.

\section{O LEGADO DA TEORIA PURA DO DIREITO}

Não há como negar a originalidade e o ineditismo da construção teórica de Hans Kelsen. O jurista austríaco representa um marco divisor na História do Direito. Antes de Kelsen havia uma espécie de sincretismo metodológico, sem que houvesse um método que coordenasse, de modo linear, aspectos elementares do Direito. A ideia de Justiça, não raras vezes, confundia-se com Direito positivo, notadamente se fundada em balizas oriundas do Direito natural. Ao mesmo tempo, havia correntes do pensamento jurídico que apregoavam um apego excessivo à letra da 
lei como a panacéia para todos problemas da vida em sociedade, o que também era uma ilusão.

É por isto que o pensamento de Kelsen se destaca. Ele fez uma ruptura com as orientações então firmadas ao expor uma linha teórica própria, peculiar, autêntica, formal e coerente. Sua Teoria Pura deixa claro o que deve ser entendido por Direito; onde e quando o justo e o injusto devem ser objeto de discussão e o porquê disso. A Teoria Pura elucida e proporciona, mediante um sistema escalonado, como aferir a validade e invalidade das normas jurídicas, sem incorrer no risco de engessamento do Direito.

Kelsen, por ser um neokantiano, rompeu com qualquer linha de pensamento fundada no Direito natural, no psicologismo, no sociologismo, no axiologismo. Seu intento consistia em alcançar a segurança jurídica que se espera do Direito. Segurança jurídica que é um dos pilares do Direito, sem o qual este não cumpre seu propósito de imprimir normas a bem orientar o convívio social humano. Neste particular, cumpre lembrar que discussões sobre Justiça ou Moral, dada a relatividade destas, são intermináveis e jamais alcançarão um consenso universal, o que não contribui para a segurança jurídica.

No entanto, a vida flui e o ser humano, como ser político que é, no sentido aristotélico do vocábulo, carece do Direito para se relacionar com seus semelhantes. Além disso, o ser humano necessita ter consigo o sentimento de segurança; precisa de um sentido em sua vida. Sobre este tema, vale transcrever as observações de Vilém Flusser:

Uma das ânsias fundamentais do espírito humano em sua tentativa de compreender, governar e modificar o mundo é descobrir uma ordem. Um mundo caótico seria incompreensível, portanto careceria de significado e seria ocioso querer governá-lo e modificá-lo. A própria existência humana não passaria de um dos elementos dos quais o caos se compõe, seria fútil. Um mundo caótico, embora concebível, é, portanto, insuportável. O espírito, em sua 'vontade de poder', recusa-se a aceitá-lo. Procura, no fundo 
das aparências caóticas, uma estrutura graças à qual as aparências, caoticamente 'complicadas' possam ser 'explicadas'. (FLUSSER, 2007, p. 31).

É aqui que Kelsen revela ser um grande conhecedor da natureza e da condição humana. Conhecedor não só de sua ânsia de segurança, mas de todas as contradições que este mesmo ser humano traz em si e as projeta em seus relacionamentos, de modo que o Direito tem um papel essencial na vida social e na própria vida pessoal de qualquer pessoa, na medida em que ordena a sociedade, proíbe condutas e garante direitos.

Atento a isto, Kelsen elabora um sistema jurídico em condições de atender a estes anseios sociais e individuais, sem colidir o sentimento de segurança almejado.

Isto não implica dizer que suas linhas teóricas são infalíveis, perfeitas e não passíveis de críticas; adaptações ou correções. Pelo contrário, a Teoria Pura apresenta vários aspectos polêmicos e discutíveis, caso da Norma Fundamental, da ruptura extremada entre Direito positivo e Moral, Justiça ou Política; e, ainda, a não abordagem profunda dos conceitos jurídicos abertos, caso dos princípios, dos conceitos jurídicos indeterminados e das cláusulas gerais.

Seja como for, antes de tecer críticas sobre seu trabalho, é necessário ter presente que o propósito de Kelsen foi o de construir bases para uma autêntica ciência jurídica em consonância com a segurança jurídica.

É preciso lembrar que Kelsen foi um positivista normativista, não um positivista primitivo como por vezes é reputado. Sua Teoria Pura expôs um positivismo jurídico aprimorado, rompendo com vários dogmas do positivismo clássico e com outras correntes jusfilosóficas de sua época.

É imperativo rememorar, por derradeiro, que Kelsen jamais foi um pós-positivista. Seu intento não consistiu em apresentar uma Teoria Interpretativa do Direito, muito menos uma Teoria da Decisão Judicial. Seu propósito - destaque-se - consistiu em formular uma estrutura articulada, uma construção sistemática, formal, coerente e congruente para o ordenamento jurídico. Uma construção dotada de uma metodologia própria, específica e rigorosa. Neste sentido, o legado de sua Teoria Pura 
do Direito é inquestionável.

\section{CONCLUSÕES}

Do desenvolvimento do tema, foram extraídas as seguintes conclusões:

1. A Teoria Pura do Direito é toda assentada nos fundamentos do Direito. Conhecê-la significa conhecer mais de Direito e do Direito.

2. Kelsen objetivava apresentar bases sólidas para uma legítima ciência do Direito. Uma ciência dotada de universalidade, própria das ciências em geral. A Teoria Pura do Direito é sua obra magna neste desígnio.

3. Para Kelsen ciência jurídica e Direito não se confundem. O Direito não é uma ciência, mas é objeto de estudo de uma ciência: a ciência do Direito. A ciência do Direito conhece e estuda o seu objeto: o Direito positivo. O que é puro não é o Direito, e sim a ciência do Direito.

4. Ao estabelecer o Direito positivo como objeto da ciência do Direito, Kelsen exclui deste objeto quaisquer influências de ordem política, ética, psicológica, metafísica etc., haja vista que estes podem comprometer a objetividade e a neutralidade do cientista.

5. A ciência do Direito equivale à metalinguagem e se propõe a descrever e analisar o Direito positivo que é a linguagem -objeto, daí advém os conceitos de norma jurídica (Rechtsnorm) e de proposição jurídica (Rechtssatz), os quais serão essenciais na atividade do cientista do Direito para aferir a validade, ou não, da 
norma jurídica.

6. As leis naturais e as normas jurídicas pertencem a ontologias diversas e, assim, devem receber tratamento diverso no plano científico. Logo, se nas ciências naturais prevalece o princípio da causalidade - ser (Sein) -, nas ciências jurídicas impera o princípio da imputação - dever ser (Sollen).

7. Kelsen jamais foi contra a Justiça no Direito. Em verdade, Kelsen não acreditava em uma Justiça absoluta. Para ele toda visão de Justiça é relativa e varia de pessoa para pessoa; no tempo e no espaço. Diante disso, para existir uma ciência do Direito, não há como incluir a Justiça. O trabalho do cientista do Direito consiste em descrever o objeto estudado (Direito positivo), e não em realizar uma valoração deste. A concepção de Justiça está excluída da ciência do Direito, e não do Direito positivo.

8. Para Kelsen "todo e qualquer conteúdo pode ser Direito." Logo, a discussão sobre a justiça ou injustiça da norma jurídica está circunscrita ao momento de ingresso deste conteúdo no Direito positivo, e não na atuação do cientista jurídico.

9. O sistema jurídico se estrutura em dois planos: estático e dinâmico. O estático permite realizar uma inspeção da norma jurídica em si. O dinâmico analisa as relações de coordenação e subordinação das normas jurídicas sob o prisma hierárquico e escalonado que sustém o ordenamento jurídico. Por este enfoque, será válida a norma que estiver em consonância com a que lhe é superior e assim sucessivamente até culminar na Norma Fundamental (Grundnorm), que não é posta (Direito positivo), mas pressuposta; fundamento de 
validade de todo o ordenamento jurídico.

10. Kelsen era um grande conhecer da natureza e condição humanas. Em decorrência disso, buscou formular uma Teoria para o Direito que, em meio às carências, aspirações e contradições humanas, preservasse a segurança jurídica que se espera do Direito.

11. O grande legado da Teoria Pura do Direito de Hans Kelsen consistiu em apresentar uma estrutura articulada, sistemática, formal, coerente e congruente para o ordenamento jurídico, além de uma metodologia própria, específica e rigorosa para a ciência do Direito.

\section{REFERÊNCIAS}

BITTAR, Eduardo C. B. e ALMEIDA, Guilherme, Assis de. Curso de Filosofia do Direito. 8. ed. São Paulo: Atlas, 2010.

CAPELLA, Juan-Ramon. El Derecho como Lenguage. Barcelona: Ariel, 1968.

CARNIO, Henrique Garbellini. Direito e Antropologia. Reflexões do Direito a partir de Kelsen e Nietzsche. São Paulo: Saraiva, 2013.

FERRAZ JR. Tércio Sampaio. Introdução ao Estudo do Direito. Técnica, Decisão, Dominação. 2. ed. São Paulo: Atlas, 1994.

GRAU, Eros Roberto. Direito Posto e Direito Pressuposto. 7. ed. São Paulo: Malheiros, 2008.

FLUSSER, Vilém. Língua e Realidade. 3. ed. São Paulo: Annablume, 2007. 
HONESKO, Vítor Hugo Nicastro. A Norma Jurídica e os Direitos Fundamentais. Um discurso sobre a crise do Positivismo Jurídico. São Paulo: RCS Editora, 2006.

IHERING, Rudolf Von. A Luta pelo Direito. Tradução de Pietro Nassetti. 2. ed. São Paulo: Martin Claret, 2000.

KELSEN, Hans. Teoria Pura do Direito. Tradução de João Baptista Machado. São Paulo: Martins Fontes, 2000.

. O que é Justiça? Tradução de Luís Carlos Borges. São Paulo: Martins Fontes, 2001.

. Autobiografía. Traduccíon de Luis Villar Borda. Bogotá: Universidad Externado de Colombia, 2008. Edição Kindle.

LARENZ, Karl. Metodologia da Ciência do Direito. Tradução de José Lamego. Lisboa: Fundação Calouste Gulbenkian, 2009.

MATOS, Andityas Soares de Moura Costa. Filosofia do Direito e Justiça na Obra de Hans Kelsen. $2^{\mathrm{a}}$ ed. Belo Horizonte: Del Rey, 2006.

NOVELLI, Mariano. H. Las ideas de Kirchmann acerca de la ciencia jurídica. Consideraciones sobre epistemología y derecho. Revista del Centro de Investigaciones en Filosofia Juridica y Filosofia Social.v. 29, p. 103-109, 2006.

SGARBI, Adrian. Clássicos de Teoria do Direito. 2. ed. Rio de Janeiro: Lumen Juris, 2009.

REALE, Miguel. Lições Preliminares de Direito. 16. ed. São Paulo: Saraiva, 1988. 
ROBLES, Gregorio. Presentación à Teoría Pura del Derecho. Introducción a Los Problemas de la Ciencia Jurídica. Primera Edición de 1934. Madrid: Trotta, 1934.

VILANOVA, Lourival. Causalidade e Relação no Direito. 4. ed. São Paulo: Revista dos Tribunais, 2000.

Como citar: VIANNA, José Ricardo Alvarez. A ciência (pura) do direito em Hans Kelsen. Revista do Direito Público, Londrina, v. 11, n. 2, p.82-108, ago. 2016. DOI: 10.5433/1980-511X.2016v11n2p82. ISSN: 1980-511X.

Submetido em 25/08/2016

Aprovado em 28/08/2016 